\title{
1 Diversity of Archaea Domain in Cuatro Cienegas Basin: Archaean Domes
}

3 Medina-Chávez Nahui Olin¹, Viladomat-Jasso Mariette ${ }^{2}$, Olmedo-Álvarez Gabriela ${ }^{3}$, Eguiarte Luis

$4 \quad \mathrm{E}^{2}$, Souza Valeria ${ }^{2}$, De la Torre-Zavala Susana ${ }^{1,4}$

5

6 1Universidad Autónoma de Nuevo León, Facultad de Ciencias Biológicas, Instituto de

7 Biotecnología. Av. Pedro de Alba S/N Ciudad Universitaria. San Nicolás de los Garza, Nuevo León,

8 México. C.P. 66455.

$9 \quad{ }^{2}$ Instituto de Ecología, UNAM, Circuito Exterior S/N anexo Jardín Botánico exterior. Ciudad

10 Universitaria, Ciudad de México, C.P. 04500

$11{ }^{3}$ Departamento de Ingeniería Genética, Centro de Investigación y de Estudios Avanzados del I.P.N.

12 Campus Guanajuato, AP 629 Irapuato, Guanajuato 36500, México

13

$14{ }^{4}$ Correspondence should be addressed to Susana De la Torre-Zavala;

15 susana.delatorrezv@uanl.edu.mx.

16 


\section{Abstract}

24 Herein we describe the Archaea diversity in a shallow pond in the Cuatro Ciénegas Basin (CCB),

25 Northeast Mexico, with fluctuating hypersaline conditions containing elastic microbial mats that

26 can form small domes where their anoxic inside reminds us of the characteristics of the Archaean

27 Eon, rich in methane and sulfur gases; thus, we named this site the Archaean Domes (AD). These

28 domes only form after heavy rains that are rare in the Chihuahuan desert. CCB is a unique oasis

29 with hundreds of ponds, containing endemic species of animals, plants and highly diverse and

30 unique microbial communities, despite its very biased stoichiometry, due mostly to extreme low

31 phosphorus content (soils, water columns and sediments). This extreme oligotrophy has favored

32 survival of ancestral microorganisms. Whole metagenome sequencing approach was performed for

33 this unusual site in three different seasons to assess the extent of the Archaea biodiversity, with a

34 focus on extremophiles, since members of the Archaea had been underrepresented in different study

35 sites within the oasis. We found a highly diverse Archaea community compassing 5\% of the

36 metagenomes. The archaeal portion in all three metagenomes maintained its abundance and most of

37 the strains showed to form a resilient core during three seasonal samplings (2016-2017), despite

38 environmental fluctuations. However, relative abundances of all 230 archaeal OTUs (defined using

39 a 97\% cutoff) were low enough $(<0.1 \%)$ to be considered part of the rare biosphere. AD finding and

40 their description within CCB confirms that this particular pond is the most diverse for Archaea that

41 we are aware of and opens new paths for understanding the forces that once drove and keep shaping

42 microbial community assemblage. 


\section{Introduction}

47 The Archaea domain is an essential but usually rare, component of different ecosystems, not only

48 extreme ones as originally suggested [1-4], for instance, they are critical in hydrological systems

49 and their abundance and composition changes according to identifiable spatial and temporal scales

50 [5-7]. Archaea is represented in 26 phyla [8], most of which are novel and some lineages include

51 only one species of uncultivated strains that have been assembled through metagenomics [9, 10].

52 Indeed, a current challenge in their study is the isolation and cultivation of novel Archaea, since

53 they are usually restricted to extreme conditions. Traditional culture-dependent approaches have

54 underestimated abundance and diversity of Archaea, making it hard to achieve an accurate

55 understanding of their role in microbial communities in an ecological niche [11]. Nevertheless, a

56 successful co-cultivation of an Asgard archaeon associated with bacteria was reported after a long-

57 term methane-fed bioreactor culture of deep marine sediments, demonstrating that non-traditional

58 cultures of untapped environments are reservoirs of Archaea genetic and functional diversity yet to

59 be uncovered [12]. Another challenge is to fully comprehend their phylogenetic association, given

60 the limited genetic information available for some Archaea phyla.

61 In the last decade, our knowledge on the diversity and taxonomy of Archaea has

62 substantially improved [13] due to the rise of metagenomics and increasing available archaeal

63 genomes. The Archaea tree is being rapidly filled up with new branches, demonstrating that the

64 Archaea domain remains largely unexplored [14] along with a diverse metabolism [15, 16],

65 unveiling new processes and key features involving microbes and community structure.

66 Cuatro Cienegas Basin (CCB) is an endangered oasis within the northern zone of the

67 Chihuahuan Desert in Mexico, characterized by an extremely unbalanced nutrient stoichiometry of

68 the area $(\mathrm{N}: \mathrm{P}=159: 1)$, similar to the conditions of the Precambrian sea [17-21]. Strikingly, despite 
69 this nutrient deficiency CCB is considered a biodiversity hotspot for macroorganisms [22] and one

70 of the most diverse sites for microorganisms in the world [23-27]; this microbial biodiversity is

71 mirrored by its extreme diversity in virus [28]. CCB biodiversity is believed to have evolved as a

72 result of a long time environmental stability of a deep aquifer [29], as suggested by the marine

73 affiliations in many of the studied bacterial genomes [25, 30], virus [31], and probably, Archaea.

74 These observations led CCB scientists to raise hypothesis and propose CCB as a model of "lost

75 world", where extreme conditions favored the survival of ancestral marine lineages that in some

76 cases persist exclusively in this area [32]. Nevertheless, Archaea in CCB has been poorly studied

77 since they were underrepresented in previous metagenomic studies [24, 28, 33, 34].

During a late March 2016 field work, an atypical spring rain apparently dissolved the salty

79 crust of an unnoticed shallow pond, allowing the uniquely flexible and impermeable microbial mats

80 to arise from the ground building bubbles, or domes with a strong sulfur-like smell. Our hypothesis

81 was that gas production of methanogenic as well as other microorganisms associated to the sulfur

82 cycle were degassing creating a locally anaerobic atmosphere. Therefore, the anaerobic layer of the

83 microbial mats were creating the domes by raising the flexible and impermeable mat where

84 photosynthesis was evident given the purple, and green layers, creating an unique "alien" local

85 landscape (Figure 1). Based on the macroscopic morphology of the microbial mats, this locality in

86 the Pozas Azules ProNatura ranch (a private ecological reserve) was named by us the "Archean

87 Domes" (AD thereafter) (Fig. 1a).

88 These unusual structures in an small extremophilic and fluctuating pond, are by themselves a

89 singularity, within CCB unique nature and amazing microbial diversity that has fascinated scientists

90 with unexpected findings [19-21, 25, 27, 29, 30, 33, 35-43]. High salt concentration in dry

91 conditions, and the production of biogases along dome formation under wet conditions, suggested 
92 that this fluctuating evaporitic hypersaline microbial mat would be an ideal place to explore the

93 Archaea diversity in CCB.

94 Considering the taxonomic profiling of different ponds previously studied within the Cuatro

95 Cienegas system along 20 years [17, 28, 30, 33, 37-39, 41, 44-53], a working hypothesis was

96 proposed for the community composition of $\mathrm{AD}$ microbial mat: that each sample would be unique,

97 given the drastic environmental fluctuations. A null hypothesis would predict that the AD

98 community would constitute a unique community with a constant core community, able to construct

99 the domes given the right environmental conditions (heavy rain). In order to explore these

100 hypotheses for the Archaea domain, a whole genome metagenomic approach was applied to explore

101 the community shaping the AD microbial mat, expecting to achieve a coverage depth sensitive

102 enough for the rare biosphere. Sampling for AD was done in three seasons (dry-wet-dry).

103

As mentioned above, Archaea had not been observed to be diverse or abundant in CCB,

104 however, we found in this study that the Archaean Domes displayed an abundant and diverse

105 archaeal community. Even more, they represent one of the most diverse archaeal communities

106 known up to date in the world. Unexpectedly, this diversity is not only very large given the small

107 geographical scale of this site (at $\mathrm{cm}^{2}$ level), but it is constant along all sampling seasons. This

108 novel window to the Archaea world will be a biodiversity resource that may provide us with paths

109 to understand the uniqueness that CCB lost world represents for ecology, evolution, systematics and

110 future bioprospecting studies.

\section{2. Material and Methods}

113 2.1 Sampling site. Water and sediment were obtained from the Archaean Domes (AD) in Rancho

114 Pozas Azules, from Pronatura Noreste (26 49' 41.7" N 102 01' 28.7" W) in CCB, under 
115 SEMARNAT scientific permit No. SGPA/DGVS/03121/15 (Figure 1). Sampling took place during

116 2016-2017 at the following times: April 2016 (dry, AD1), September 2016 (wet, AD2), February

1172017 (dry, AD3); microbial mats and sediments $\left(8 \mathrm{~cm}^{2}\right)$ were transferred to sterile conical tubes (50

$118 \mathrm{~mL}$ ) and used for metagenomic analysis.

1192.2 Metadata.

120 Following the National Meteorological System data base for the Pozas Azules ranch weather station

121 (Supplementary material), we observed that in March 2016, there was an anomalous spring rain

122 peak $(90 \mathrm{~mm})$ that apparently allowed us to discover the AD. The $10^{\text {th }}$ of April sampling occurred

123 when maximum air temperatures where $\sim 30^{\circ} \mathrm{C}$, and the domes were drying. In average,

124 precipitation in early fall, reached $48 \mathrm{~mm}$ in September 2016, during our wet sampling date, and no

125 rain were detected during February 2017, making it another dry sampling. The water

126 physicochemical conditions were measured in September 2016 sampling, using a Hydrolab MS5

127 Water multiparameter sonde (OTT Hydromet GmbH, Germany) (Supp. Table 1). Other sampling

128 dates were not tested due to the lack of water in the ponds (see Figure 1).

1292.3 Total DNA Extraction. Extraction of total DNA from Archaean domes sediment was performed

130 in Experimental and Molecular Evolution Laboratory of the Ecology Institute, UNAM as reported

131 before [24] using a modification of Purdy et al. (1996) [54] protocol.

$132 \quad 2.4$ Metagenomic Shotgun Sequencing. Total DNA from sediment of the three seasoned samples

133 (AD1, AD2, and AD3) were sent to CINVESTAV- LANGEBIO, Irapuato, Mexico, for shotgun

134 whole genome sequencing using Illumina Mi-Seq 2x300 technology.

1352.5 Bioinformatic analysis for metagenomes. Raw data from AD1, AD2 and AD3, was quality

136 checked using FastQC (http://www.bioinformatics.babraham.ac.uk/projects/fastqc). Indexed adapter

137 and barcodes were removed and low quality sequences were discarded with Trimmomatic v0.36

138 using a sliding window of $4 \mathrm{pb}$ and an average quality per base of 25 [55], followed by the merging 
139 of the paired end reads using PEAR software [56]. Once reads were merged, both paired ends

140 assembled and unassembled reads were used to cover major accuracy to obtain relative abundance

141 for Eukarya, Bacteria and Archaean species using MetaPhlAn2 software [57].

$142 \quad 2.6$ Diversity analysis and species accumulation curve. Using normalized relative abundances of

143 Archaean taxa within each metagenome, $\alpha$ and $\beta$ diversity were calculated using EstimateS 9.1.0

144 and Past Software, respectively [58, 59].

1452.7 Phylogenetic analysis. Reference 16S rRNA sequences were downloaded from the NCBI- Gen

146 Bank and RNA Central Database according to identifications of MetaPhlAn2 hits. The sequences

147 were aligned with ClustalW [60] and trimmed using MEGA V 7.0 [61]. The phylogeny was

148 reconstructed with a Maximum Likelihood (ML) algorithm in MEGA and K-2 + G (Kimura 2-

149 parameter + gamma distribution) evolutionary model with 10,000 bootstraps. Also reference strains

150 were added to supply a robust interpretation.

1512.8 Identification number of Metagenomic Data. The identification number for the metagenomic

152 data used in this study are available in MG-RAST with the following ID: AD 1: mgm4856917.3,

153 mgm4856915.3; AD 2: mgm4856913.3, mgm4856914.3; AD 3: mgm4856916.3, mgm4856918.3,

154 and also using the following link: https://www.mg-rast.org/linkin.cgi?project=mgp90438.

155

156

157

158

159

160

161 


\section{Results}

\section{3.1. The "Archaean Domes" are hypersaline non-lithifying microbial mats.}

165 After obtaining the necessary collecting permits and adequate equipment, sample collection of the

166 AD was conducted in early April 2016. By then, the AD site was starting to dry, and the mat

167 exhibited a morphology in which a photosynthetic upper layer became evident in the dome-like

168 structure, while the interior of the domes maintained a wet black layer (Fig. 1b). Physicochemical

169 and environmental conditions of AD were registered on April 2016, September 2016, and February

170 2017, that is, during dry and wet conditions (Table 1 and Supp. Table 1). Further observations (not

171 shown) after four years revealed that during the dry seasons, AD microbial mats are active even if

172 they do not produce domes. Moreover, it is only after heavy rains dissolve the salts, that domes

173 emerge due to the elastic nature of the mats, producing its typical sulfur-like smell. We have

174 observed the same phenomena up to last exploration September 2019.

175 The AD mats sampled on April $10^{\text {th }}, 2016$, looked different from the original observation

176 (less than 3 weeks earlier). What firstly seemed like a shallow pond, was already drying up when

177 the first sample was collected for sequencing (AD1), and the dense salty liquid started to turn into a

178 salty-white-carbonate crust. As can be seen in Figure 1C, in, the second sampling (AD2, September

179 2016) represented a more wet environment, and the site looked similar to the one observed

180 originally (i.e., March 2016), although the domes were smaller. The last sample of this study was

181 collected in February 2017, by the end of the cold-dry season (AD3).

182 The microbial community of the AD is approximately $200 \mathrm{~m}$ away from the most described,

183 stromatolite-rich and iconic blue pond from Rancho Pozas Azules, but physicochemical conditions

184 found in the $\mathrm{AD}$ are extreme in salinity and higher in $\mathrm{pH}$ (Table 1). While Blue Pond $\mathrm{pH}$ is 7.9 [62, 
185 63], $\mathrm{pH}$ of $\mathrm{AD}$ almost peaks 10. Moreover, in the first sampling (AD1), salinity was 53\%, and it

186 reached saturation later in that year, when the upper layer of the mat became a white salty crust,

187 which prevented measurement with the available equipment for consistent results. Considering all

188 the above, we can describe the AD as a hypersaline microbial mat [64].

3.2. The Archaea domain in the Archaean Domes.

191 The Illumina MiSeq run of 300-bp paired-ends delivered 28,859,454 reads for AD1, 24,772,053

192 reads for AD2 and 28,203,484 reads for AD3 of total DNA metagenomics, which were normalized

193 for bioinformatic analysis. The percentage for relative abundance of the Archaea domain in AD1,

$194 \mathrm{AD} 2$, and AD3, were 3.6\%, 5\% and 5\% respectively. The binning of the metagenomic reads

195 showed that the archaeal community in the AD metagenomes was dominated by Euryarchaeota-

196 halophilic archaeal lineages. Sequences from Crenarchaeota, Thaumarchaeota, Korarchaeota, and

197 Nanoarchaeota phyla were also retrieved (Fig. 2). All five phyla comprise 15 classes dominated by

198 members of Halobacteria and Methanomicrobia classes (Fig. 2), both important groups of the

199 Euryarchaeota phylum. Additionally, 25 orders, 36 families, 93 genera, and 230 species (defined as

200 OTUs at $97 \%$ cutoff) were detected in the three metagenomes. It is noteworthy that from those 230

201 OTUs, a total of 24 could not be further classified (Supp. Fig.2).

202 To depict the extent of the biodiversity present within the AD metagenomes, we retrieved

203 from the marker databases the 16S rRNA sequences corresponding to the species identified by

204 MetaPhlAn2. We used these sequences to reconstruct a phylogeny (Fig. 3). Several sequences

205 belonging to the same genera were omitted to avoid redundancy; others without a full-length marker

206 sequence were also omitted. The phylogenetic reconstruction displays 213 sequences, 169

207 belonging to our mining and 44 are reference sequences. Five phyla were represented, that gave rise 208 to 11 major clades. 
Alpha diversity was calculated using Shannon, Simpson and Chao indexes (Table 2a).

210 Compared to the fluctuations observed in several bacterial studies in CCB [65], the archaeal

211 diversity did not show drastic changes through sampling seasons (Table 2a). Moreover, 90\% of the

212 total archaeal richness (OTUs at 97\% cutoff level) is shared among the three samples. This is

213 confirmed by the Beta diversity estimates at species level (Table 2 b). Overall, richness evaluated at

214 the other different taxonomic levels (i.e., using the 15 classes, the 25 orders, and/or the 36 families)

215 of Archaea, remain similar in the three metagenomes.

216 In accordance with the Archaea's stable core hypothesis for the AD, the species

217 accumulation curve shows that the inventory for every sample (AD1, AD2, AD3) was very similar.

218 The expected diversity using the presence and absence for every identified OTUs in the

219 metagenomic analysis increased very little with the addition of each sample. Therefore, OTU

220 rarefaction curve with data from the 3 samples is asymptotic (Suppl. Fig. 1).

\subsection{The Archaean Domes Rare Biosphere.}

223 Considering that 229 of the 230 identified archaeal OTUs are each present at relative abundances

224 below $0.1 \%$, we applied a strict threshold of $0.01 \%$ of relative abundance [66] to identify what we

225 consider strictly rare archaeal taxa. Consequently, within the AD mats, 50 archaeal OTUs were

226 defined to be strictly rare (each covering less than $<0.01 \%$ of the total reads). Interestingly, such

227 abundance profiles along the three sampling times show that 11 OTUs of the strictly rare Archaea

228 taxa seem to be conditionally rare [67], that is, these taxa maintain their lower abundance in only

229 one sample, and reach higher (while still rare <0.1\%) abundances in other samples (Fig. 3A). This

230 suggests that while the rest of the Archaea community is relatively stable, the strictly rare biosphere

231 is dynamic and depends on the proper conditions to prosper. On the other hand, we found that 39

232 strictly rare Archaea OTUs were not detected in at least one metagenome (Fig. 3B). These taxa 
233 exhibiting this kind of fluctuation along time series are considered transiently rare taxa [68]. Notice

234 that sample season 2 (wet) shows a peak of transient rare taxa, suggesting that it is possible that

235 dome construction during wet conditions can benefit by this change in population dynamics, while

236 other taxa seem to prosper in the extremely salty environment.

\section{Discussion}

239 The microbial community that constitute the AD microbial mats is indeed unique among the studied

240 CCB bacterial communities [21], displaying a relative high abundance of Archaea in AD1, AD2,

241 and AD3, that reached 3.6\%, 5\% and 5\% respectively. Those abundances are remarkable for such a

242 small sampled area $\left(\mathrm{cm}^{2}\right)$, but also when compared to other sites in CCB and the world (see Table

243 1) [69-71]. After profiling the community at several taxonomic levels, it was observed that an

244 archaean community core remained almost intact in time (April 2016-February 2017). This

245 provided evidence for stability behind the construction of the domes (our null hypothesis).

246 Nevertheless, within that core, the diversity and proportions of rare archaeal taxa increased or

247 diminished across seasons, exhibiting a dynamic in the AD which might be playing a role for their

248 functioning along different environmental conditions.

\subsection{The Archaean Domes at CCB are a good model of the Archaean period, and are one of the}

\section{1 most abundant and diverse environments for Archaea.}

252 Microbial mats and stromatolites are considered analogues of early Earth, when they originated as

253 successful ecological communities, capable of complete nutrient cycling as soon as life started to

254 diversify in the early Archean Eon $[72,73]$. Different ancestral lineages have survived at CCB [21,

255 30], purportedly because they have adapted continuously to their neighbors, forming very tight 
256 communities that cohesively survive despite the changing harsh abiotic factors, like those

257 experienced along their very long evolutionary trajectory [21]. We believe, that the microbial mat of

$258 \mathrm{AD}$ is not an exception in $\mathrm{CCB}$, however, the observation that raised scientific interest to study

259 these particular mats was precisely its extreme conditions of $\mathrm{pH}$ and salinity, besides their

260 interesting "architectural" shape. Notwithstanding, analogue extreme environmental conditions

261 have been reported in other archaeal rich microbial mats before, for instance in the Desert of

262 Atacama or the human made salterns in Guerrero Negro, both stable environments (Table 1) show

263 much lower Archaea diversity [69-71]. A possibility is that the fluctuating environment in AD are

264 part of the community dynamics increasing possible niches, and it has been observed within CCB in

265 other fluctuating environments that harbor large diversity due to local adaptations to each condition

$266[37,74]$. However, the AD mat is peculiar because Archaea are more abundant and diverse than in

267 other fluctuating microbialites within CCB [62] (Table 1). Moreover, this is the first site where

268 there is a constant microbial core despite the environmental fluctuations among seasons. Not only

269 Archaea diversity within AD is relatively constant, it is also considerably large for a metagenomic

270 study using the Illumina platform [75].

271 On the other hand, targeted clone libraries for Archaean primers have revealed a high

272 abundance of Archaea ( 10\%) in stromatolites communities of the Hammelin Pool in SharkBay,

273 Australia, which reaches one of the highest archaeal abundances. However, such archaeal

274 community was represented by 27 archaeal clones, out of 176 total of $16 \mathrm{~S}$ rRNA clone library from

275 a single sample point [76]. These numbers are hard to compare to our observed AD archaeal

276 diversity due to different experimental approaches. Other archaeal-rich hypersaline microbial mats

277 show relative abundances of Archaea that range from 4\% in a mat in Camargue, Spain. [77], 9\% in

278 Guerrero Negro hypersaline mat [78], 20\% in some layers of the microbial mat in a shallow pond in 
279 the Salar de Llamara [79], and above $90 \%$ of 16S rRNA of sequences amplified in a highly lithified 280 mat in Laguna de Tebenchique, in the Salar de Atacama [69]. Nevertheless, all these Archaea-rich 281 sites, display lower diversity [80] than our small $\left(\mathrm{cm}^{2}\right)$ seasonal AD. Given the extremely small 282 site, our 230 different species (at 97\% cutoff) and 5 different phyla can be considered high. 283 Noticeably, our 24 unclassified archaeal OTUs (Supp. Figure 2), constitute an interesting challenge 284 for systematics and biodiscovery.

The CCB is well known for its outstanding microbial diversity and unique endemic lineages $[25,28,35,40,74,81]$ that have been isolated from the rest of the world; this uniqueness may be in part the result of its extremely biased stoichiometry $[17,19,44]$. Success of archaeal communities 288 in the AD may rely on physiological adaptations that could for instance allow them to out-compete 289 bacteria in specific niches with low energy or nutrients availability [82]. However, previously 290 studied localities within CCB displaying the same low energy stress, such as Pozas Rojas microbial 291 mat, lack similar numbers of Archaea. Pozas Rojas exhibits extreme N:P ratios (156:1), and also 292 fluctuating environments [33]. Despite all of the above, until AD were uncovered, archaeal 293 abundances and diversity had not been reported before as a distinctiveness in any of the numerous 294 explored sites within CCB [24, 27, 28, 35]. The abundance of Euryarchaeota members (halophiles 295 and methanogens) may be related to the high-carbonate, salty-crust upper layer, and the black 296 methanogenic bottom strata, acting as barriers on both sides on the mat. The estimated $\alpha$ and $\beta$ diversity indexes for the AD samples suggest resilience of the 298 community, which is expected to be largely influenced by species diversity, as explained by the 299 insurance hypothesis [83]. Our data shows a slight increase in archaeal diversity and richness 300 indexes in dry seasons compared to the sample from the wet season (Table 2), possibly because that 
301 is the usual state of the AD site, since annual precipitations are not heavy enough to dissolve the

302 salts and change the ecology of the mats (Supp. Table 1)

304 domain in the $\mathrm{AD}$ mats is the killing-the-winner hypothesis [84], that proposes a negative

305 frequency-dependent selection, in which bacterial types are affected by viral pressure, promoting 306 the survival and viability of rare types, and thus maintaining high diversity. Viral reads in our AD 307 metagenomes represent a relative abundance ranging from $23.3 \%$ to $31.6 \%$, which is remarkably 308 high compared to other metagenomes, and even higher than typical virus-rich environments, such as 309 those obtained from samples of filtered sea water in South Korea [85], several deep sea sediments 310 [86] and microbialites from SharkBay, Australia [71].

4.2 The rare biosphere in the AD community.

313 Rare biosphere may represent a reservoir of genetic diversity that actively responds to

314 environmental changes [87]. Given the predominance of an equitable rare biosphere in all the

315 previously sampled sites of CCB [24], and the extreme and unpredictable conditions of the AD site, 316 we considered it was important to explore rarity within the Archaea community.

317 By defining a "strictly rare" biosphere as the taxa with relative abundances below $0.01 \%$, we 318 found 50 archaeal OTUs. Within this group, 11 OTUs seem to be conditionally rare [67],

319 maintaining their lower abundance in only one sampling time (the wet month), and reaching higher 320 abundances in both dry samplings (Fig. 3A). Their dynamics lead us to speculate that those rare 321 OTUs from the AD, along with the more abundant OTUs, could be benefiting of a saltier 322 environment or drier conditions. In both cases, it is noticeable that although archaeal richness and 323 overall abundance does not change much among samples, it is the rare (the one driven by 
324 environmental fluctuations) biosphere that exhibits variations. A similar response to cold versus

325 warm conditions have been noticed in other systems within CCB [37].

Among this rare biosphere, some taxa were found to be transiently rare (i.e., absent in one or

327 two of the samples) comprising 39 OTUs (Fig. 3B). We suggest that this type of rarity should be

328 driven at least in part by stochastic processes, such as passive dispersal of lineages temporarily

329 recruited from microbial seed bank, or due to immigration [88]. As an example, nine rare

330 unclassified taxa that were not present or were in very low abundances in the initial sample AD1,

331 became abundant in February sample (dry season) (Fig. 3; Suppl. Fig. 2). More metagenomic

332 studies are in their way to explore such pattern in a longer time frame.

It should not be discarded that the lowest-abundant taxa of $\mathrm{AD}$ could be undergoing

334 dormancy, a mechanism that maintains cells alive, but inactive and intermittently below detection

335 thresholds [89]. Indeed, Archaea can enter a cellular dormant state [89-91], thereby providing an

336 adaptive response to what would otherwise be a deleterious environmental perturbation. This has

337 been experimentally studied analyzing the thermoacidophile archaeon Metallosphaera prunae that

338 produces VapC toxins that drive cellular dormancy under uranium stress [92]. Another factor for

339 dormancy in Archaea is predatory organisms, specifically, virus, which are abundant in the AD

340 metagenomes ( $28 \%)$. As an example, a research group showed that rare and even inactive viruses,

341 induce dormancy in the model archaeon Sulfolobus islandicus [90]. Also oligotrophy might be

342 playing a role in Archaea dormancy, as dormant bacteria taxa have been found to be enriched in

343 low phosphorus environment [89] and dormant microorganisms can also escape virus predation

344 [93]. Considering the extremely skew stoichiometry, virus may be the drivers of the community

345 structure, not only liberating immobilized nutrients to the system by lysing cells, but by maintaining

346 a large panoply of rare taxa coexisting and avoiding predation. 


\subsection{Halophiles and methanogens Archaea in the AD}

349 Halophiles and methanogens species were highly abundant in the AD, representing $>50 \%$ of the 350 total Archaeal diversity. The relationship between halophiles and methanogens is well known,

351 sharing a common ancestral habitat $[78,82,94,95]$ and both groups are found in microbial mats

352 and microbial communities associate to precipitated minerals (endoevaporites) [70]. The

353 methanogens living in the aforementioned environments need a high level of $\mathrm{NaCl}(0.5 \mathrm{M})$ for

354 optimal growth [96] and usually are halotolerant or halophilic [97]. This type of hypersaline

355 environments is very dynamic and wide spread in the world [98].

356 In our sampling site, halophilic and methanogenic Archaea are proposed to constitute the

357 stable core of the AD during hypersaline conditions under the salt crust. Accordingly, other studies

358 indicate that salinity is the major abiotic factor that allows the shaping of microbial communities,

359 especially in sediment surfaces, stromatolites, hydrothermal vents, hypersaline mats and anoxic

360 saline water. These studies have demonstrated that saline sediments contain communities with

361 higher unique biodiversity values in comparison with other environments [99]. Other studies

362 demonstrate that changes in salinity, sulfate and availability of substrates could possibly stimulate

363 the production of methane [70].

The most abundant OTUs in the analyzed AD metagenomes were similar to

\section{Methanohalophilus mahii, a halophilic-methanogen Archaea described as a non-marine}

366 methanogen, adapted to hypersaline environments; its metabolism requires $1.0-2.5 \mathrm{M} \mathrm{NaCl}$ for

367 optimal growth and methanogenesis, using methanol and methylamines as substrates [95]. Other

368 OTUs from AD were related to Natrialba taiwanensis, Haloferax sulforifontis, Methanoplanus

369 petrolearius and Haloterrigena thermotolerans. Halophilic and methanogen species coexisted

370 within the microbial mat, along with some unexpected genera belonging to Euryarchaeota phylum.

371 Among the latter we can find, Thermococcus, Natronomonas, Picrophylus, Archaeoglobus, 
372 Aciduliprofundum and even Thermoplasma, a lineage that lacks a cell wall. These microorganisms

373 are mostly reported from hydrothermal vents, displaying a high level of tolerance to low and high

374 temperatures and a wide range of $\mathrm{pH}[100,101]$. The presence of these taxa along with the

375 previous observations, adds evidence to our proposal stating that CCB microbial communities have

376 both marine and magmatic affinities [30,32]. Therefore, the Archaea that we observed in AD are

377 witness of both environments, the deep aquifer propelled by magmatic heat within the mountain of

378 San Marcos y Pinos [29], and the surface life, where photosynthesis occurs, rarely, after rainy days.

379 Hence, part of the AD diversity might have emerged from the deep sediments that contained the

380 mineral conditions of the ancient ocean [52].

381

\subsection{Thermophilic and other related Archaea lineages in the AD}

383 Summing to the hypothesis of magmatic influence to the microbial community of this unusual site,

384 Crenarchaeota taxa are consistently present in the AD mat. These include thermophilic genera such

385 as Thermoproteus, Caldivirga, Ignicoccus, Sulfolobus, Pyrolobus, among others. In addition,

386 Thaumarchaeota members were detected, such as "Candidatus Nitrososphaera gargensis”,

387 Nitrosoarchaeum limnia, and Marine Group 1 Thaumarchaeota. The presence of two OTUs were

388 unexpected: Cenarchaeum symbiosum, a psycrophillic archaeon, previously reported as a symbiont

389 of a several sponge species [102], and Nitrosopumilus maritimus, considered ubiquitous on

390 oligotrophic oceans [103], another AD finding consistent with the marine signatures frequently

391 found in CCB microbes [25, 28, 30, 44, 53]. The same occurs with "Candidatus Korarchaeota

392 cryptophilum", a representative of Korarchaeota phylum, its presence in AD is related to the marine

393 origin of CCB and an incoming colonization of geothermal-terrestrial environments, a feature

394 shared among the thermophiles [104]. 
Both Crenarchaeota and Thaumarchaeota have in general terms similar metabolic

396 capabilities. PCR-amplified amoA genes from DNA of each sample (AD1, AD2, AD3; data not

397 shown) provided evidence of ammonia oxidation capabilities as potential energy source and

398 nitrification [105], suggesting a role for chemolithotrophy of these taxa in CCB, using a large

399 panoply of organic compounds as well as $\mathrm{CO}_{2}$, iron, nitrogen and sulfur compounds as electron

400 acceptors, as for instance methanobacteria (Euryarchaeota) and hyperthermophilic Crenarchaeota

401 members use sulfur as an electron acceptor [106].

402 Other unexpected but interesting member of the phyla in the AD metagenomes were the

403 Nanoarchaeota Nanoarchaeum equitans, a small-sized archaeon and an ectoparasitic relationship

404 with the Crenarchaeota Ignicoccus, which was also detected in the sample [107]. Nanoarchaeaota

405 phylum has a widespread habitat distribution with diverse physicochemical features compatible

406 with hot springs and other mesophilic hypersaline environments [108].

\section{5. Perspectives and conclusions.}

409 The Archaean Domes microbial mats at the oasis Cuatro Ciénegas Basin, were recently discovered

410 as a hypersaline extreme site. In these mats we uncovered through metagenomic analysis, one of

411 the highest diversities registered so far in the Archaea domain, considering the site's geographic

412 small scale. Most of the 230 OTUs observed in this unusual small shallow temporal pond, are part

413 of the rare biosphere and form a stable core community. Within this core, we observed halophiles

414 and methanogens, but also spatially unexpected archaeal taxa, that thrive under high salt

415 concentrations. We also observed a transient rare biosphere that appears to be enriched under dry

416 environmental conditions, suggesting seasonal dynamics shaping community assemblage.

417 In order to explore this group of taxonomic the unclassified rare taxa more carefully, we are in the

418 process of analyzing more metagenomes in different seasons as well as manipulating the 
419 environment using mesocosms experiments. More sequencing effort in deep sediment cores will

420 also help to look for the deep anaerobic biosphere, as well as eliminate blind spots in phylogeny of

421 unclassified Archaea, and this will require differential coverage binning approach [109] using all

422 available metagenomes from the AD to describe phylogenetic novelty within $\mathrm{AD}$ at $\mathrm{CCB}$.

423 This highly diverse ecosystem within Cuatro Cienegas, Mexico, arises as an attractive novel

424 site for evolutionary, ecological, astrobiological and bioprospecting studies. The AD is, so far, the

425 most diverse microbial community found in CCB, despite its extreme conditions. Since this area is

426 being subjected to intense water exploitation by agricultural practices, and desiccation has become a

427 common occurrence in numerous ponds, it is priority for our research group to keep investigating

428 the ecology of the adaptation of this highly diverse archaeal-rich microbial communities to

429 fluctuating temperature and rainfall conditions, while working with shareholders on changes in

430 policy of water usage.

431 Now proven as an archaeal rich extreme site, CCB is once more attracting attention as an

432 astrobiological model [38, 41]. The Archaean Domes not only can take us further back into the "lost

433 world" but it is also a site that keeps providing evidences and new keys to understand how "life

434 cycle" could have been originated on Earth, or (will be) possible on, for example, Mars.

\section{Conflicts of interest}

437 The authors declare that there is no conflict of interest regarding the publication of this paper.

\section{Acknowledgments}

440 We want to thank to Hamlet Aviles-Arnaut, Gabriel Moreno-Hagelsieb for their critical review of

441 the manuscript. Also, thanks to Hamlet Avilés-Arnaut, Irene Ruvalcaba-Ortega and Ricardo

442 Canales-Del Castillo for their valuable technical support and critical observations throughout the 
443 project. Thanks to Kendra Rivera and Josué Corona for their technical help on the experiments.

444 Finally, we thank SEMARNAT and APFF Cuatro Ciénegas for facilitating the sampling and in

445 particular Rancho Pozas Azules, PRONATURA Noreste for access and permission to sample in the

446 CCB Natural Protected Area.

449 Funding Statement

450 We thank Universidad Autónoma de Nuevo León for funding field work through the PAICYT

451 program granted to Susana De la Torre-Zavala during 2015. We thank the Alianza WWF-

452 Fundación Carlos Slim fund to Valeria Souza and Luis E. Eguiarte.

References

(1) B. J. Baker, J. H. Saw, A. E. Lind, et al., "Genomic inference of the metabolism of cosmopolitan subsurface Archaea, Hadesarchaea," Nature Microbiology, vol. 1, pp. $16002,2016$.

462

463

464

465

466

467

468

469

(2) E. F. DeLong, "Everything in moderation: Archaea as 'non-extremophiles'," Current Opinion in Genetics \& Development, vol. 8, no. 6, pp. 649-654, 1998.

(3) J.-C. Auguet, A. Barberan, E. O. Casamayor, “Global ecological patterns in uncultured Archaea," The Isme Journal, vol. 4, pp. 182, 2009.

(4) B. Chaban, S. Y. Ng, K. F. Jarrell, "Archaeal habitats--from the extreme to the ordinary," Can J Microbiol, vol. 52, no. 2, pp. 73-116, 2006.

(5) M. J. Church, E. F. DeLong, H. W. Ducklow, et al., "Abundance and distribution of planktonic Archaea and Bacteria in the waters west of the Antarctic Peninsula," Limnology and Oceanography, vol. 48, no. 5, pp. 1893-1902, 2003. 
471

472

473

474

475

476

477

478

479

480

481

482

483

484

485

486

487

488

489

490

491

492

493

494

495

496

497

498

499

500

501

502

503

504

505

506

507

508

509

510

511

512

513

514

515

516

(6) M. A. Martinez-Olivas, N. G. Jimenez-Bueno, J. A. Hernandez-Garcia, et al., "Bacterial and archaeal spatial distribution and its environmental drivers in an extremely haloalkaline soil at the landscape scale," PeerJ, vol. 7, pp. e6127, 2019.

(7) Y. Chen, Y. Liu, X. Wang, "Spatiotemporal variation of bacterial and archaeal communities in sediments of a drinking reservoir, Beijing, China," Appl Microbiol Biotechnol, vol. 101, no. 8, pp. 3379-3391, 2017.

(8) L. A. Hug, B. J. Baker, K. Anantharaman, et al., "A new view of the tree of life," Nature Microbiology, vol. 1, pp. 16048, 2016.

(9) S. Kato, S. Nakano, M. Kouduka, et al., "Metabolic Potential of As-yet-uncultured Archaeal Lineages of Candidatus Hydrothermarchaeota Thriving in Deep-sea Metal Sulfide Deposits," Microbes Environ, 2019.

(10) J. M. Huang, B. J. Baker, J. T. Li, Y. Wang, "New Microbial Lineages Capable of Carbon Fixation and Nutrient Cycling in Deep-Sea Sediments of the Northern South China Sea," Appl Environ Microbiol, vol. 85, no. 15, 2019.

(11) K. G. Lloyd, A. D. Steen, J. Ladau, J. Yin, L. Crosby, "Phylogenetically Novel Uncultured Microbial Cells Dominate Earth Microbiomes," mSystems, vol. 3, no. 5, 2018.

(12) H. Imachi, M. K. Nobu, N. Nakahara, et al., "Isolation of an archaeon at the prokaryoteeukaryote interface," bioRxiv, pp. 726976, 2019.

(13) C. Petitjean, P. Deschamps, P. López-García, D. Moreira, C. Brochier-Armanet, "Extending the Conserved Phylogenetic Core of Archaea Disentangles the Evolution of the Third Domain of Life," Molecular Biology and Evolution, vol. 32, no. 5, pp. 1242$1254,2015$.

(14) P. S. Adam, G. Borrel, C. Brochier-Armanet, S. Gribaldo, "The growing tree of Archaea: new perspectives on their diversity, evolution and ecology," The Isme Journal, vol. 11, pp. 2407, 2017.

(15) C. Bräsen, D. Esser, B. Rauch, B. Siebers, "Carbohydrate metabolism in Archaea: current insights into unusual enzymes and pathways and their regulation," Microbiology and molecular biology reviews : MMBR, vol. 78, no. 1, pp. 89-175, 2014.

(16) S. Thor, J. R. Peterson, Z. Luthey-Schulten, "Genome-Scale Metabolic Modeling of Archaea Lends Insight into Diversity of Metabolic Function," Archaea, vol. 2017, pp. 9763848, 2017.

(17) J. J. Elser, J. H. Schampel, F. Garcia-Pichel, et al., "Effects of phosphorus enrichment and grazing snails on modern stromatolitic microbial communities," Freshwater Biology, vol. 50, no. 11, pp. 1808-1825, 2005.

(18) J. J. Elser, J. Watts, J. H. Schampel, J. Farmer, "Early Cambrian food webs on a trophic knife-edge? A hypothesis and preliminary data from a modern stromatolite-based ecosystem," Ecology Letters, vol. 9, no. 3, pp. 295-303, 2006.

(19) V. Souza, L. E. Eguiarte, J. Siefert, J. J. Elser, "Microbial endemism: does phosphorus limitation enhance speciation?," Nat Rev Microbiol, vol. 6, no. 7, pp. 559-564, 2008.

(20) J. Elser, J. Okie, Z. Lee, V. Souza, "The Effect of Nutrients and N:P Ratio on Microbial Communities: Testing the Growth Rate Hypothesis and Its Extensions in Lagunita Pond (Churince)," in Ecosystem Ecology and Geochemistry of Cuatro Cienegas: How to Survive in an Extremely Oligotrophic Site, F. García-Oliva, J. Elser and V. Souza, Eds., pp. 31-41, Springer International Publishing, 2018.

(21) V. Souza, A. Moreno-Letelier, M. Travisano, et al., "The lost world of Cuatro Cienegas Basin, a relictual bacterial niche in a desert oasis," Elife, vol. 7, 2018. 
517

518

519

520

521

522

523

524

525

526

527

528

529

530

531

532

533

534

535

536

537

538

539

540

541

542

543

544

545

546

547

548

549

550

551

552

553

554

555

556

557

558

559

560
(22) W. L. Minckley, Environments of the Bolson of Cuatro Cienegas, Coahuila, Mexico., Texas Western Press, THE UNIVERSITY OF TEXAS AT EL PASO 1969.

(23) V. Souza, L. E. Eguiarte, J. J. Elser, M. Travisano, G. Olmedo-Álvarez, "A Microbial Saga: How to Study an Unexpected Hot Spot of Microbial Biodiversity from Scratch?," in Cuatro Ciénegas Ecology, Natural History and Microbiology, V. Souza, G. Olmedo-Álvarez and L. E. Eguiarte, Eds., pp. 1-20, Springer International Publishing, 2018.

(24) V. De Anda, I. Zapata-Peñasco, L. E. Eguiarte, V. Souza, "Toward a Comprehensive Understanding of Environmental Perturbations in Microbial Mats from the Cuatro Cienegas Basin by Network Inference," in Ecosystem Ecology and Geochemistry of Cuatro Cienegas: How to Survive in an Extremely Oligotrophic Site, F. García-Oliva, J. Elser and V. Souza, Eds., pp. 85-97, Springer International Publishing, 2018.

(25) H. F. Arocha-Garza, R. Canales-Del Castillo, L. E. Eguiarte, V. Souza, S. De la TorreZavala, "High diversity and suggested endemicity of culturable Actinobacteria in an extremely oligotrophic desert oasis," PeerJ, vol. 5, pp. e3247, 2017.

(26) Z. Gomez-Lunar, M. Vázquez-Rosas-Landa, G. Y. Ponce-Soto, et al., "How Divergent Is the Cuatro Ciénegas Oasis? Genomic Studies of Microbial Populations and Niche Differentiation," in Cuatro Ciénegas Ecology, Natural History and Microbiology, V. Souza, G. Olmedo-Álvarez and L. E. Eguiarte, Eds., pp. 57-71, Springer International Publishing, 2018.

(27) P. Velez, J. Gasca-Pineda, E. Rosique-Gil, et al., "Microfungal oasis in an oligotrophic desert: diversity patterns and community structure in three freshwater systems of Cuatro Cienegas, Mexico," PeerJ, vol. 4, pp. e2064, 2016.

(28) B. Taboada, P. Isa, A. L. Gutierrez-Escolano, et al., "The Geographic Structure of Viruses in the Cuatro Cienegas Basin, a Unique Oasis in Northern Mexico, Reveals a Highly Diverse Population on a Small Geographic Scale," Appl Environ Microbiol, vol. 84, no. 11, 2018.

(29) B. D. Wolaver, L. J. Crossey, K. E. Karlstrom, et al., "Identifying origins of and pathways for spring waters in a semiarid basin using $\mathrm{He}, \mathrm{Sr}$, and $\mathrm{C}$ isotopes: Cuatrocienegas Basin, Mexico," Geosphere, vol. 9, no. 1, pp. 113-125, 2013.

(30) A. Moreno-Letelier, G. Olmedo-Alvarez, L. E. Eguiarte, V. Souza, "Divergence and phylogeny of Firmicutes from the Cuatro Cienegas Basin, Mexico: a window to an ancient ocean," Astrobiology, vol. 12, no. 7, pp. 674-684, 2012.

(31) C. Desnues, B. Rodriguez-Brito, S. Rayhawk, et al., "Biodiversity and biogeography of phages in modern stromatolites and thrombolites," Nature, vol. 452, no. 7185, pp. 340$343,2008$.

(32) V. Souza, A. Moreno-Letelier, M. Travisano, et al., "The lost world of Cuatro Ciénegas Basin, a relictual bacterial niche in a desert oasis," eLife, vol. 7, pp. e38278, 2018.

(33) M. Peimbert, L. D. Alcaraz, G. Bonilla-Rosso, et al., "Comparative metagenomics of two microbial mats at Cuatro Cienegas Basin I: ancient lessons on how to cope with an environment under severe nutrient stress," Astrobiology, vol. 12, no. 7, pp. 648-658, 2012.

(34) G. Bonilla-Rosso, M. Peimbert, L. D. Alcaraz, et al., "Comparative metagenomics of two microbial mats at Cuatro Cienegas Basin II: community structure and composition in oligotrophic environments," Astrobiology, vol. 12, no. 7, pp. 659-673, 2012. 
bioRxiv preprint doi: https://doi.org/10.1101/766709; this version posted September 12, 2019. The copyright holder for this preprint (which was not certified by peer review) is the author/funder, who has granted bioRxiv a license to display the preprint in perpetuity. It is made available under aCC-BY-NC-ND 4.0 International license.

561

562

563

564

565

566

567

568

569

570

571

572

573

574

575

576

577

578

579

580

581

582

583

584

585

586

587

588

589

590

591

592

593

594

595

596

597

598

599

600

601

602

603

604

605

(35) V. Souza, L. Espinosa-Asuar, A. E. Escalante, et al., "An endangered oasis of aquatic microbial biodiversity in the Chihuahuan desert," Proc Natl Acad Sci U S A, vol. 103, no. 17, pp. 6565-6570, 2006.

(36) B. M. Winsborough, E. Theriot, D. B. Czarnecki, "Diatoms on a continental "island": Lazarus species, marine disjuncts and other endemic diatoms of the Cuatro Cienegas basin, Coahuila, Mexico.," Nova Hedwigia, Suppl, vol. 135, pp. 257-274, 2009.

(37) A. Rodriguez-Verdugo, V. Souza, L. E. Eguiarte, A. E. Escalante, "Diversity across Seasons of Culturable Pseudomonas from a Desiccation Lagoon in Cuatro Cienegas, Mexico," Int J Microbiol, vol. 2012, pp. 201389, 2012.

(38) V. Souza, J. L. Siefert, A. E. Escalante, J. J. Elser, L. E. Eguiarte, "The Cuatro Cienegas Basin in Coahuila, Mexico: an astrobiological Precambrian Park," Astrobiology, vol. 12, no. 7, pp. 641-647, 2012.

(39) V. Souza, L. E. Eguiarte, M. Travisano, et al., "Travel, sex, and food: what's speciation got to do with it?," Astrobiology, vol. 12, no. 7, pp. 634-640, 2012.

(40) E. A. Rebollar, M. Avitia, L. E. Eguiarte, et al., "Water-sediment niche differentiation in ancient marine lineages of Exiguobacterium endemic to the Cuatro Cienegas Basin," Environ Microbiol, vol. 14, no. 9, pp. 2323-2333, 2012.

(41) N. E. Lopez-Lozano, L. E. Eguiarte, G. Bonilla-Rosso, et al., "Bacterial communities and the nitrogen cycle in the gypsum soils of Cuatro Cienegas Basin, coahuila: a Mars analogue," Astrobiology, vol. 12, no. 7, pp. 699-709, 2012.

(42) S. Pajares, L. E. Eguiarte, G. Bonilla-Rosso, V. Souza, "Drastic changes in aquatic bacterial populations from the Cuatro Cienegas Basin (Mexico) in response to longterm environmental stress," Antonie Van Leeuwenhoek, vol. 104, no. 6, pp. 1159-1175, 2013.

(43) S. Pajares, A. E. Escalante, A. M. Noguez, et al., "Spatial heterogeneity of physicochemical properties explains differences in microbial composition in arid soils from Cuatro Cienegas, Mexico," PeerJ, vol. 4, pp. e2459, 2016.

(44) L. D. Alcaraz, G. Olmedo, G. Bonilla, et al., "The genome of Bacillus coahuilensis reveals adaptations essential for survival in the relic of an ancient marine environment," Proc Natl Acad Sci U S A, vol. 105, no. 15, pp. 5803-5808, 2008.

(45) J. Toribio, A. E. Escalante, J. Caballero-Mellado, et al., "Characterization of a novel biosurfactant producing Pseudomonas koreensis lineage that is endemic to Cuatro Cienegas Basin," Syst Appl Microbiol, vol. 34, no. 7, pp. 531-535, 2011.

(46) N. E. Lopez-Lozano, K. B. Heidelberg, W. C. Nelson, et al., "Microbial secondary succession in soil microcosms of a desert oasis in the Cuatro Cienegas Basin, Mexico," PeerJ, vol. 1, pp. e47, 2013.

(47) G. Y. Ponce-Soto, E. Aguirre-von-Wobeser, L. E. Eguiarte, et al., "Enrichment experiment changes microbial interactions in an ultra-oligotrophic environment," Front Microbiol, vol. 6, pp. 246, 2015.

(48) J. A. Valdivia-Anistro, L. E. Eguiarte-Fruns, G. Delgado-Sapien, et al., "Variability of rRNA Operon Copy Number and Growth Rate Dynamics of Bacillus Isolated from an Extremely Oligotrophic Aquatic Ecosystem," Front Microbiol, vol. 6, pp. 1486, 2015.

(49) N. J. Felstead, M. J. Leng, S. E. Metcalfe, S. Gonzalez, "Understanding the hydrogeology and surface flow in the Cuatrociénegas Basin (NE Mexico) using stable isotopes," Journal of Arid Environments, vol. 121, pp. 15-23, 2015. 
606

607

608

609

610

611

612

613

614

615

616

617

618

619

620

621

622

623

624

625

626

627

628

629

630

631

632

633

634

635

636

637

638

639

640

641

642

643

644

645

646

647

648

649

650

651
(50) M. D. Rodriguez-Torres, A. Islas-Robles, Z. Gomez-Lunar, et al., "Phenotypic Microdiversity and Phylogenetic Signal Analysis of Traits Related to Social Interaction in Bacillus spp. from Sediment Communities," Front Microbiol, vol. 8, pp. 29, 2017.

(51) Z. M. Lee, A. T. Poret-Peterson, J. L. Siefert, et al., "Nutrient Stoichiometry Shapes Microbial Community Structure in an Evaporitic Shallow Pond," Front Microbiol, vol. 8, pp. 949, 2017.

(52) V. Souza, L. E. Eguiarte, "In the Beginning, There Was Fire: Cuatro Ciénegas Basin (CCB) and the Long History of Life on Earth," in Cuatro Ciénegas Ecology, Natural History and Microbiology, V. Souza, G. Olmedo-Álvarez and L. E. Eguiarte, Eds., pp. 21-33, Springer International Publishing, 2018.

(53) T. Aguirrezabala-Campano, O. Gerardo-Nieto, R. Gonzalez-Valencia, V. Souza, F. Thalasso, "Methane dynamics in the subsaline ponds of the Chihuahuan Desert: A first assessment," Sci Total Environ, vol. 666, pp. 1255-1264, 2019.

(54) K. J. Purdy, T. M. Embley, S. Takii, D. B. Nedwell, "Rapid Extraction of DNA and rRNA from Sediments by a Novel Hydroxyapatite Spin-Column Method," Appl Environ Microbiol, vol. 62, no. 10, pp. 3905-3907, 1996.

(55) A. M. Bolger, M. Lohse, B. Usadel, "Trimmomatic: a flexible trimmer for Illumina sequence data," Bioinformatics, vol. 30, no. 15, pp. 2114-2120, 2014.

(56) J. Zhang, K. Kobert, T. Flouri, A. Stamatakis, "PEAR: a fast and accurate Illumina PairedEnd reAd mergeR," Bioinformatics, vol. 30, no. 5, pp. 614-620, 2014.

(57) N. Segata, L. Waldron, A. Ballarini, et al., "Metagenomic microbial community profiling using unique clade-specific marker genes," Nat Methods, vol. 9, no. 8, pp. 811-814, 2012.

(58) R. K. Colwell, J. E. Elsensohn, "EstimateS turns 20: statistical estimation of species richness and shared species from samples, with non-parametric extrapolation," Ecography, vol. 37, no. 6, pp. 609-613, 2014.

(59) Ø. Hammer, D. A. Harper, P. D. Ryan, "PAST: paleontological statistics software package for education and data analysis," Palaeontologia electronica, vol. 4, no. 1, pp. 9, 2001.

(60) D. G. Higgins, "CLUSTAL V: multiple alignment of DNA and protein sequences," Methods Mol Biol, vol. 25, pp. 307-318, 1994.

(61) S. Kumar, G. Stecher, K. Tamura, "MEGA7: Molecular Evolutionary Genetics Analysis Version 7.0 for Bigger Datasets," Mol Biol Evol, vol. 33, no. 7, pp. 1870-1874, 2016.

(62) C. M. Centeno, P. Legendre, Y. Beltran, et al., "Microbialite genetic diversity and composition relate to environmental variables," FEMS Microbiol Ecol, vol. 82, no. 3, pp. 724-735, 2012.

(63) L. Espinosa-Asuar, A. E. Escalante, J. Gasca-Pineda, et al., "Aquatic bacterial assemblage structure in Pozas Azules, Cuatro Cienegas Basin, Mexico: Deterministic vs. stochastic processes," Int Microbiol, vol. 18, no. 2, pp. 105-115, 2015.

(64) H. L. Wong, A. Ahmed-Cox, B. P. Burns, "Molecular Ecology of Hypersaline Microbial Mats: Current Insights and New Directions," Microorganisms, vol. 4, no. 1, 2016.

(65) N. E. López-Lozano, S. Pajares, A. E. Escalante, et al., "Microcosms and Mesocosms: A Way to Test the Resilience of Microbial Communities in Cuatro Ciénegas," in Cuatro Ciénegas Ecology, Natural History and Microbiology, V. Souza, G. Olmedo-Álvarez and L. E. Eguiarte, Eds., pp. 83-102, Springer International Publishing, 2018.

(66) X. Jia, F. Dini-Andreote, J. Falcao Salles, "Community Assembly Processes of the Microbial Rare Biosphere," Trends Microbiol, vol. 26, no. 9, pp. 738-747, 2018. 
(67) A. Shade, S. E. Jones, J. G. Caporaso, et al., "Conditionally rare taxa disproportionately contribute to temporal changes in microbial diversity," MBio, vol. 5, no. 4, pp. e0137101314, 2014.

(68) A. Shade, P. S. McManus, J. Handelsman, "Unexpected diversity during community succession in the apple flower microbiome," MBio, vol. 4, no. 2, 2013.

(69) A. B. Fernandez, M. C. Rasuk, P. T. Visscher, et al., "Microbial Diversity in Sediment Ecosystems (Evaporites Domes, Microbial Mats, and Crusts) of Hypersaline Laguna Tebenquiche, Salar de Atacama, Chile," Front Microbiol, vol. 7, pp. 1284, 2016.

(70) J. Q. Garcia-Maldonado, A. Escobar-Zepeda, L. Raggi, et al., "Bacterial and archaeal profiling of hypersaline microbial mats and endoevaporites, under natural conditions and methanogenic microcosm experiments," Extremophiles, vol. 22, no. 6, pp. 903-916, 2018.

(71) J. Babilonia, A. Conesa, G. Casaburi, et al., "Comparative Metagenomics Provides Insight Into the Ecosystem Functioning of the Shark Bay Stromatolites, Western Australia," Front Microbiol, vol. 9, pp. 1359, 2018.

(72) T. M. Lenton, S. J. Daines, "Matworld - the biogeochemical effects of early life on land," New Phytol, vol. 215, no. 2, pp. 531-537, 2017.

(73) N. H. Sleep, "The Hadean-Archaean environment," Cold Spring Harb Perspect Biol, vol. 2, no. 6, pp. a002527, 2010.

(74) R. Cerritos, L. E. Eguiarte, M. Avitia, et al., "Diversity of culturable thermo-resistant aquatic bacteria along an environmental gradient in Cuatro Cienegas, Coahuila, Mexico," Antonie Van Leeuwenhoek, vol. 99, no. 2, pp. 303-318, 2011.

(75) M. Tessler, J. S. Neumann, E. Afshinnekoo, et al., "Large-scale differences in microbial biodiversity discovery between $16 \mathrm{~S}$ amplicon and shotgun sequencing," Sci Rep, vol. 7, no. 1, pp. 6589, 2017.

(76) D. Papineau, J. J. Walker, S. J. Mojzsis, N. R. Pace, “Composition and structure of microbial communities from stromatolites of Hamelin Pool in Shark Bay, Western Australia," Appl Environ Microbiol, vol. 71, no. 8, pp. 4822-4832, 2005.

(77) M. Berlanga, M. Palau, R. Guerrero, "Functional Stability and Community Dynamics during Spring and Autumn Seasons Over 3 Years in Camargue Microbial Mats," Front Microbiol, vol. 8, pp. 2619, 2017.

(78) C. E. Robertson, J. R. Spear, J. K. Harris, N. R. Pace, "Diversity and stratification of archaea in a hypersaline microbial mat," Appl Environ Microbiol, vol. 75, no. 7, pp. 1801-1810, 2009.

(79) A. Saghai, A. Gutierrez-Preciado, P. Deschamps, et al., "Unveiling microbial interactions in stratified mat communities from a warm saline shallow pond," Environ Microbiol, vol. 19, no. 6, pp. 2405-2421, 2017.

(80) M. E. Farias, M. C. Rasuk, K. L. Gallagher, et al., "Prokaryotic diversity and biogeochemical characteristics of benthic microbial ecosystems at La Brava, a hypersaline lake at Salar de Atacama, Chile," PLoS One, vol. 12, no. 11, pp. e0186867, 2017.

(81) A. Moreno-Letelier, G. Olmedo, L. E. Eguiarte, L. Martinez-Castilla, V. Souza, "Parallel Evolution and Horizontal Gene Transfer of the pst Operon in Firmicutes from Oligotrophic Environments," Int J Evol Biol, vol. 2011, pp. 781642, 2011.

(82) D. L. Valentine, "Adaptations to energy stress dictate the ecology and evolution of the Archaea," Nat Rev Microbiol, vol. 5, no. 4, pp. 316-323, 2007. 
698

699

700

701

702

703

704

705

706

707

708

709

710

711

712

713

714

715

716

717

718

719

720

721

722

723

724

725

726

727

728

729

730

731

732

733

734

735

736

737

738

739

740

741

742
(83) S. Yachi, M. Loreau, "Biodiversity and ecosystem productivity in a fluctuating environment: the insurance hypothesis," Proc Natl Acad Sci U S A, vol. 96, no. 4, pp. 1463-1468, 1999.

(84) C. Winter, T. Bouvier, M. G. Weinbauer, T. F. Thingstad, "Trade-offs between competition and defense specialists among unicellular planktonic organisms: the "killing the winner" hypothesis revisited," Microbiol Mol Biol Rev, vol. 74, no. 1, pp. 42$57,2010$.

(85) J. Hwang, S. Y. Park, M. Park, S. Lee, T. K. Lee, "Seasonal Dynamics and Metagenomic Characterization of Marine Viruses in Goseong Bay, Korea," PLoS One, vol. 12, no. 1, pp. e0169841, 2017.

(86) C. Corinaldesi, M. Tangherlini, A. Dell'Anno, "From virus isolation to metagenome generation for investigating viral diversity in deep-sea sediments," Sci Rep, vol. 7, no. 1, pp. 8355, 2017.

(87) S. Coveley, M. S. Elshahed, N. H. Youssef, "Response of the rare biosphere to environmental stressors in a highly diverse ecosystem (Zodletone spring, OK, USA)," PeerJ, vol. 3, pp. e1182, 2015.

(88) M. D. Lynch, J. D. Neufeld, "Ecology and exploration of the rare biosphere," Nat Rev Microbiol, vol. 13, no. 4, pp. 217-229, 2015.

(89) S. E. Jones, J. T. Lennon, "Dormancy contributes to the maintenance of microbial diversity," Proc Natl Acad Sci U S A, vol. 107, no. 13, pp. 5881-5886, 2010.

(90) M. A. Bautista, C. Zhang, R. J. Whitaker, "Virus-induced dormancy in the archaeon Sulfolobus islandicus," MBio, vol. 6, no. 2, 2015.

(91) H. Gulbudak, J. S. Weitz, "A touch of sleep: biophysical model of contact-mediated dormancy of archaea by viruses," Proceedings. Biological sciences, vol. 283, no. 1839, pp. 20161037, 2016.

(92) A. Mukherjee, G. H. Wheaton, J. A. Counts, et al., "VapC toxins drive cellular dormancy under uranium stress for the extreme thermoacidophile Metallosphaera prunae," Environ Microbiol, vol. 19, no. 7, pp. 2831-2842, 2017.

(93) L. Fernandez, A. Rodriguez, P. Garcia, "Phage or foe: an insight into the impact of viral predation on microbial communities," ISME J, vol. 12, no. 5, pp. 1171-1179, 2018.

(94) M. F. Edbeib, R. A. Wahab, F. Huyop, "Halophiles: biology, adaptation, and their role in decontamination of hypersaline environments," World J Microbiol Biotechnol, vol. 32, no. 8, pp. 135, 2016.

(95) S. Spring, C. Scheuner, A. Lapidus, et al., "The genome sequence of Methanohalophilus mahii SLP(T) reveals differences in the energy metabolism among members of the Methanosarcinaceae inhabiting freshwater and saline environments," Archaea, vol. 2010, pp. 690737, 2010.

(96) W. J. Jones, D. P. Nagle, Jr., W. B. Whitman, "Methanogens and the diversity of archaebacteria," Microbiol Rev, vol. 51, no. 1, pp. 135-177, 1987.

(97) D. R. Boone, W. B. Whitman, P. Rouvière, "Diversity and Taxonomy of Methanogens," in Methanogenesis: Ecology, Physiology, Biochemistry \& Genetics, J. G. Ferry, Ed., pp. 35-80, Springer US, 1993.

(98) J. C. Vogt, R. M. M. Abed, D. C. Albach, K. A. Palinska, "Bacterial and Archaeal Diversity in Hypersaline Cyanobacterial Mats Along a Transect in the Intertidal Flats of the Sultanate of Oman," Microb Ecol, vol. 75, no. 2, pp. 331-347, 2018. 
(99) J. Yang, L. Ma, H. Jiang, G. Wu, H. Dong, "Salinity shapes microbial diversity and community structure in surface sediments of the Qinghai-Tibetan Lakes," Sci Rep, vol.

(100) R. E. Anderson, M. L. Sogin, J. A. Baross, "Biogeography and ecology of the rare and abundant microbial lineages in deep-sea hydrothermal vents," FEMS Microbiol Ecol, vol. 91, no. 1, pp. 1-11, 2015.

(101) K. Takai, K. Horikoshi, "Genetic diversity of archaea in deep-sea hydrothermal vent environments," Genetics, vol. 152, no. 4, pp. 1285-1297, 1999.

(102) S. J. Hallam, K. T. Konstantinidis, N. Putnam, et al., "Genomic analysis of the uncultivated marine crenarchaeote Cenarchaeum symbiosum," Proc Natl Acad Sci U S A, vol. 103, no. 48, pp. 18296-18301, 2006.

(103) W. W. Metcalf, B. M. Griffin, R. M. Cicchillo, et al., "Synthesis of methylphosphonic acid by marine microbes: a source for methane in the aerobic ocean," Science, vol. 337, no. 6098, pp. 1104-1107, 2012.

(104) R. L. Miller-Coleman, J. A. Dodsworth, C. A. Ross, et al., "Korarchaeota diversity, biogeography, and abundance in Yellowstone and Great Basin hot springs and ecological niche modeling based on machine learning," PLoS One, vol. 7, no. 5, pp. e35964, 2012.

(105) M. Pester, C. Schleper, M. Wagner, "The Thaumarchaeota: an emerging view of their phylogeny and ecophysiology," Curr Opin Microbiol, vol. 14, no. 3, pp. 300-306, 2011.

(106) Y. Liu, L. L. Beer, W. B. Whitman, "Sulfur metabolism in archaea reveals novel processes," Environ Microbiol, vol. 14, no. 10, pp. 2632-2644, 2012.

(107) P. Forterre, S. Gribaldo, C. Brochier-Armanet, "Happy together: genomic insights into the unique Nanoarchaeum/Ignicoccus association," J Biol, vol. 8, no. 1, pp. 7, 2009.

(108) A. Casanueva, N. Galada, G. C. Baker, et al., "Nanoarchaeal 16S rRNA gene sequences are widely dispersed in hyperthermophilic and mesophilic halophilic environments," Extremophiles, vol. 12, no. 5, pp. 651-656, 2008.

(109) M. Albertsen, P. Hugenholtz, A. Skarshewski, et al., "Genome sequences of rare, uncultured bacteria obtained by differential coverage binning of multiple metagenomes," Nat Biotechnol, vol. 31, no. 6, pp. 533-538, 2013. 


\section{Mats.}

\begin{tabular}{|c|c|c|c|c|c|c|c|}
\hline $\begin{array}{l}\text { Microbial } \\
\text { Mat }\end{array}$ & $\underset{\%}{\text { Salinity }}$ & $\begin{array}{c}\text { Temperature } \\
\text { C }^{\text {o }}\end{array}$ & pH & $\begin{array}{c}\text { Archaea } \\
\text { relative } \\
\text { abundance \% }\end{array}$ & $\begin{array}{c}\text { Archaeal } \\
\text { OTU's } \\
(97 \%) \\
\end{array}$ & $\begin{array}{l}\text { Sequencing } \\
\text { approach }\end{array}$ & Reference \\
\hline $\begin{array}{l}\text { Archaean } \\
\text { Domes }\end{array}$ & $53 \%$ & 31.45 & 9.94 & $4.96 \%$ & 230 & $\begin{array}{c}\text { Whole } \\
\text { Genome-Shot } \\
\text { Gun Illumina } \\
\text { MiSeq }\end{array}$ & This study \\
\hline $\begin{array}{l}\text { Guerrero } \\
\text { Negro, } \\
\text { Mexico }\end{array}$ & $28 \%$ & 30 & N/A & $30.45 \%$ & 209 & $\begin{array}{l}\text { 16s rRNA Tag } \\
\text { (926F/1392R) } \\
\text { FLX Titanium } \\
\text { Roche }\end{array}$ & $\begin{array}{c}\text { García- } \\
\text { Maldonado et } \\
\text { al., } 2018\end{array}$ \\
\hline $\begin{array}{c}\text { Shark Bay, } \\
\text { Australia }\end{array}$ & $6.8 \%$ & 24.8 & 8.13 & $<1 \%$ & 13 & $\begin{array}{c}\text { Whole } \\
\text { Genome-Shot } \\
\text { Gun (Illumina } \\
\text { MySeq) } \\
\end{array}$ & $\begin{array}{c}\text { Babilonia et } \\
\text { al. } 2018\end{array}$ \\
\hline $\begin{array}{l}\text { Atacama, } \\
\text { Chile }\end{array}$ & $\begin{array}{l}10.6- \\
15 \%\end{array}$ & $23-27$ & 7.65 & $50-66 \%$ & 121 & $\begin{array}{c}\text { 16s rRNA Tag } \\
\text { (F515/R806) } \\
454 \\
\text { pyrosequencin } \\
\text { g }\end{array}$ & $\begin{array}{c}\text { Fernandez et } \\
\text { al. } 2016\end{array}$ \\
\hline
\end{tabular}


801 Table 2. Diversity indexes of the Archaean Dome Metagenomes. a) Alpha and b) beta estimator

802 indexes for specific Archaea diversity.

803

\begin{tabular}{lccc}
\hline & \multicolumn{3}{c}{ AD Metagenome Samples } \\
\hline a) Alpha diversity indicator & AD1 & AD2 & AD3 \\
\hline Shannon mean & 5.33 & 5.38 & 5.3 \\
Simpson Inv mean & 207.3 & 214.17 & 216.38 \\
Observed OTU's & 222 & 200 & 200 \\
Chao Taxa number & 207.3 & 221.57 & 254.61 \\
\hline \multicolumn{1}{c}{ b) Beta diversity Index } & AD1-AD2 & AD1-AD3 & AD2-AD3 \\
\hline Bray-Curtis & 0.69 & 0.71 & 0.84 \\
\hline
\end{tabular}

804

805

806 


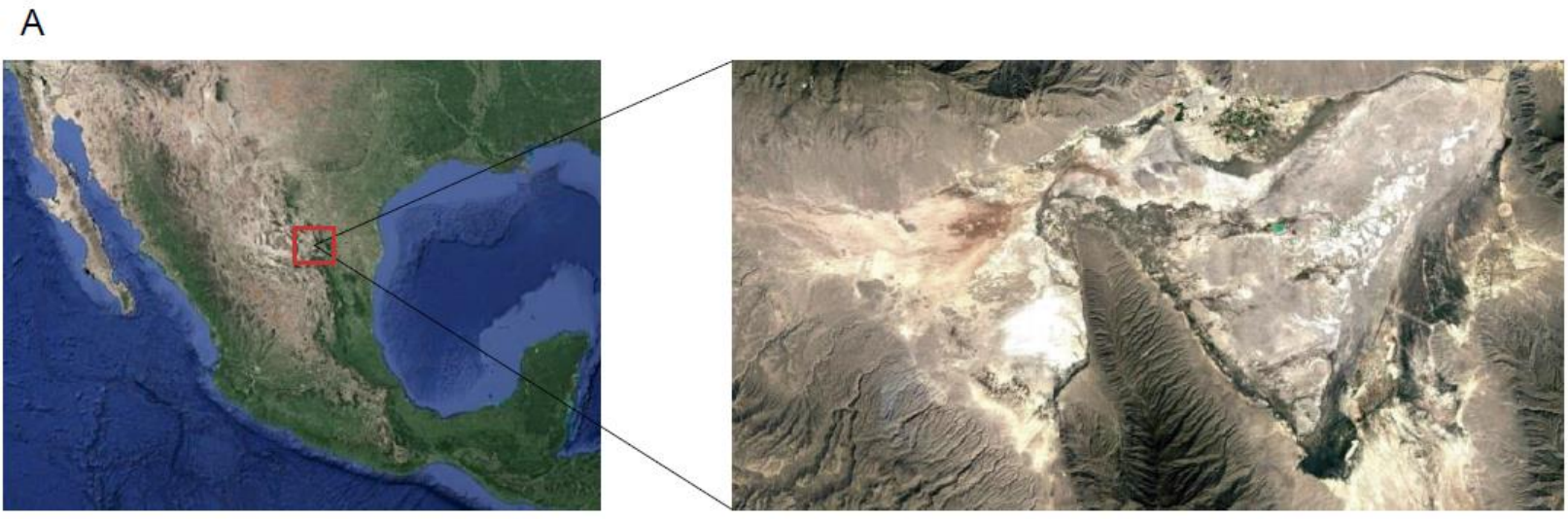

B
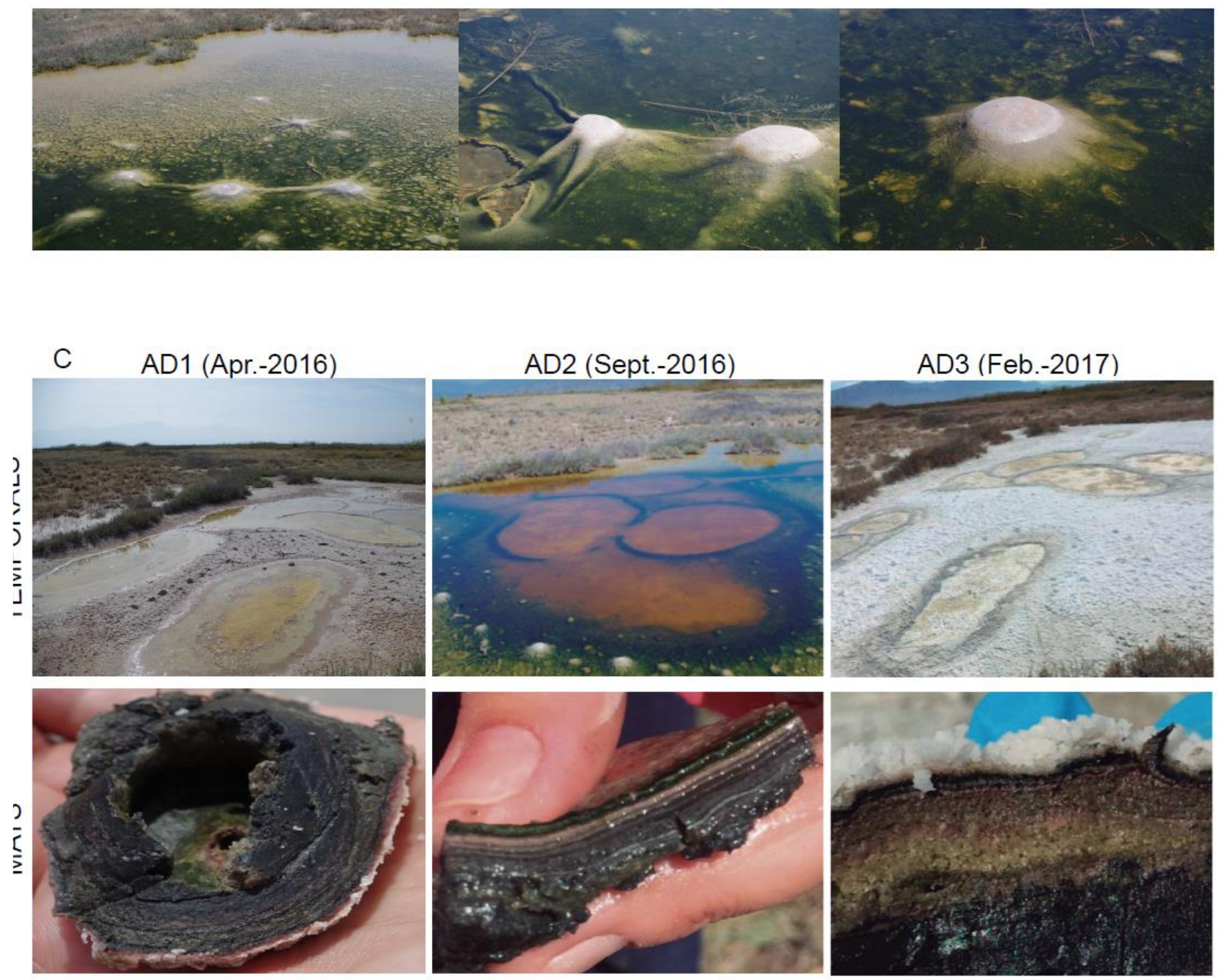
809 Figure 1. Sampling site Map. A) Cuatro Cienegas, Coahuila location within Mexico; B) Archaean

810 Domes (AD) mats with unusual and flexible bubble-containing superficial layer found in Pozas

811 Azules Ranch within Chihuahuan Desert region C) AD sampling of the three continuous seasons:

812 AD1 (April 2016), AD2 (September 2016), AD3 (February 2017) showing their obtained microbial

813 mat and the structure of microbial community in in its respective season.

814

815

816

817

818

819

820

821

822

823

824

825

826

827

828

829

830 
Community structure of Archaean Domes

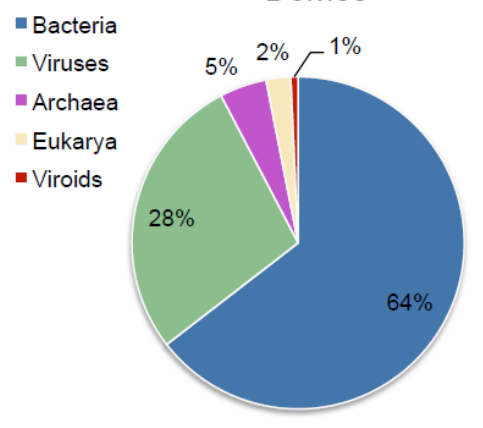

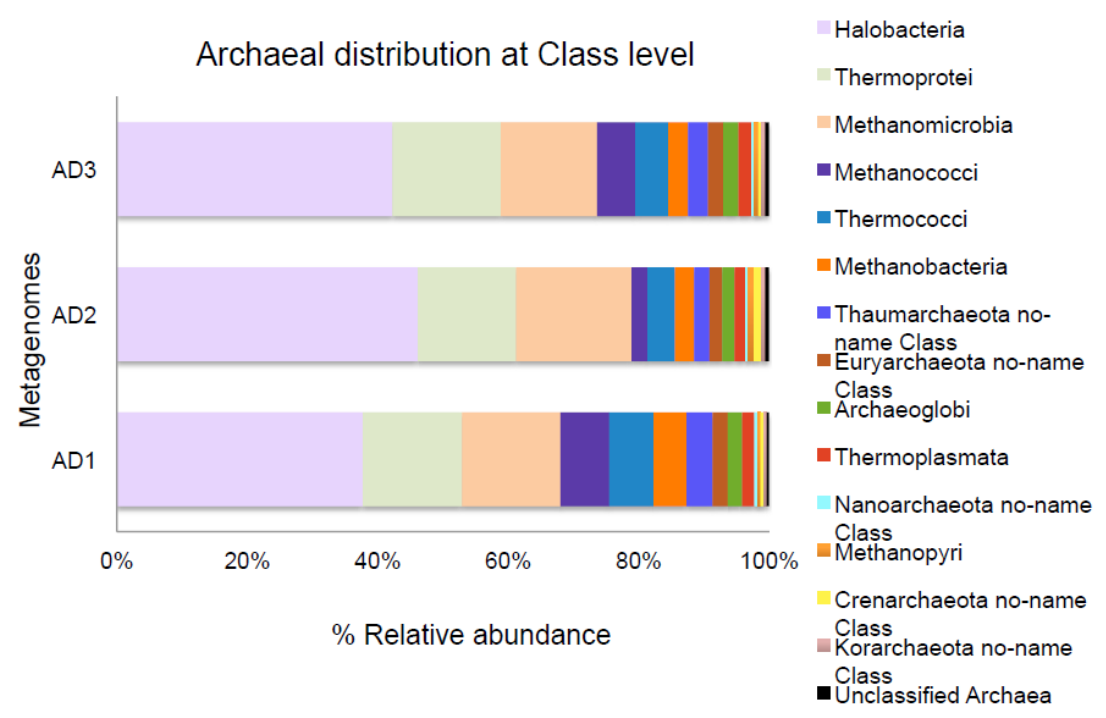

833 Figure 2. Metagenomic data of Archaean Domes. Mean Community composition (left) and

834 Class-Level distribution (right) of Archaea in the three continuous season samples of Archaean

\section{Domes.}


bioRxiv preprint doi: https://doi.org/10.1101/766709; this version posted September 12, 2019. The copyright holder for this preprint (which was not certified by peer review) is the author/funder, who has granted bioRxiv a license to display the preprint in perpetuity. It is made available under aCC-BY-NC-ND 4.0 International license.

\section{A) Conditionally Rare Archaea Taxa through AD Temporals}

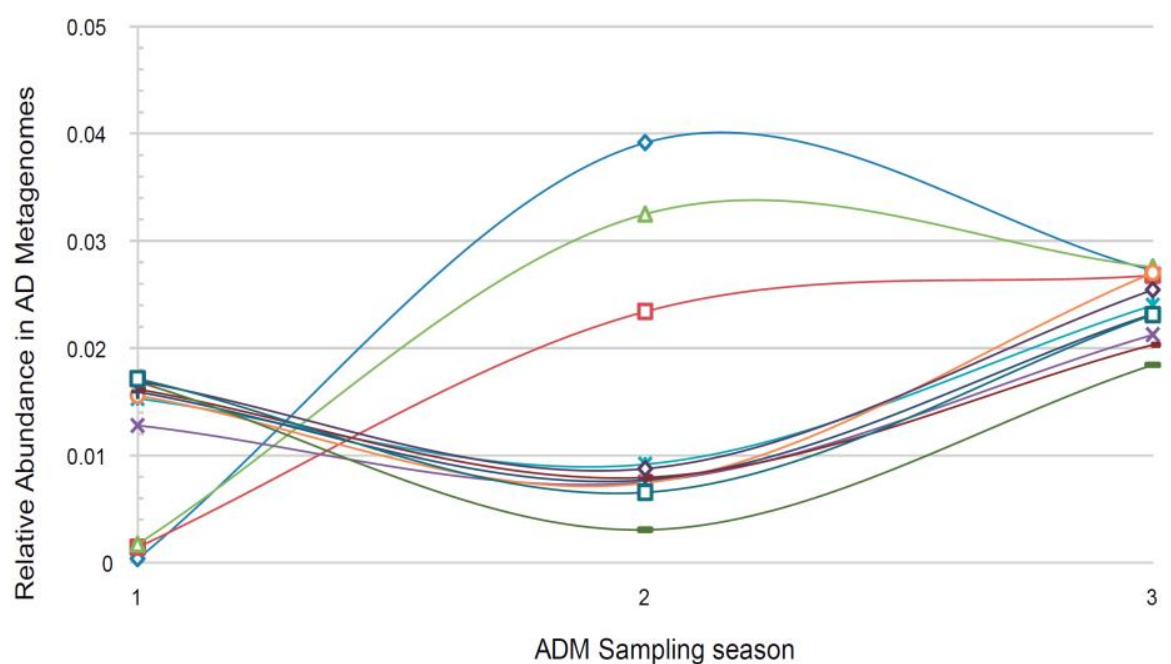

ADM Sampling season

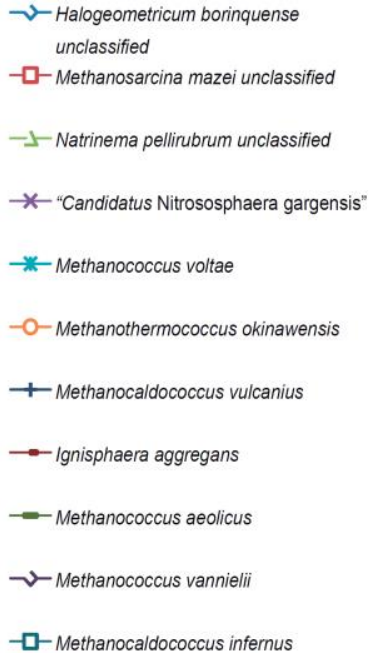

$\sim$ Crenarchaeota_archaeon

$-\square-$ Methanococcus maripaludis unclass

$\rightarrow$ Aciduliprofundum boonei unclass

*-Haloquadratum walsby unclass

- Haloferax mediterranei unclass

- - Methanoplanus limnicola

- Haloferax volcanii unclass

-- "Candidatus Nitrosoarchaeum limnia unclass"

- Nitrosopumilus sp

$\neg$-Haloquadratum walsbyi

$-\square$-Natrinema pellirubrum

$\rightarrow$ Halogeometricum_borinquense

* Salinarchaeum sp

-Haloquadratum_walsbyi

- - Vulcanisaeta distributa

-Thermococcus sp 4557

- Haloquadratum sp J07HQX50

-Methanobacterium sp Maddingley MBC34

$\sim$-Haloferax $s p$

- - Halonotius sp

-1 Methanosarcina maze

*-Methanobacterium sp SWAN1

-- "Candidatus Nitrosoarchaeum limnia"

-O-Methanobacterium sp AL21

- Pyrococcus sp NA2

- Haloferax mediterranei

- Halorubrum sp

$\neg$ Thermococcus sp CL1

$-\square-$ Methanobrevibacter $s p$

-1 "Candidatus Nitrosoarchaeum limnia"

* Haloferax volcanii unclass

-Pyrococcus sp STO4

-o-Methanocaldococcus villosus

3 - Thermococcus sp AM4

- Methanococcus maripaludis C7

- Halobacterium $s p$

$\checkmark$ Aciduliprofundum boone

$-\square$-Methanocaldococcus sp

$-\downarrow$ Methanococcus maripaludis C5 
845 Figure 3: Archaean rare biosphere. A) Relative abundance of Conditionally Rare archaeal taxa

846 through seasons in the Archaean Domes. B) Relative abundance of the Transiently Rare archaeal

847 taxa through seasons in the Archaean Domes.

848

849

850

851

852

853

854

855

856

857

858 
bioRxiv preprint doi: https://doi.org/10.1101/766709; this version posted September 12,2019 . The copyright holder for this preprint (which was not certified by peer review) is the author/funder, who has granted bioRxiv a license to display the preprint in perpetuity. It is made available under aCC-BY-NC-ND 4.0 International license.

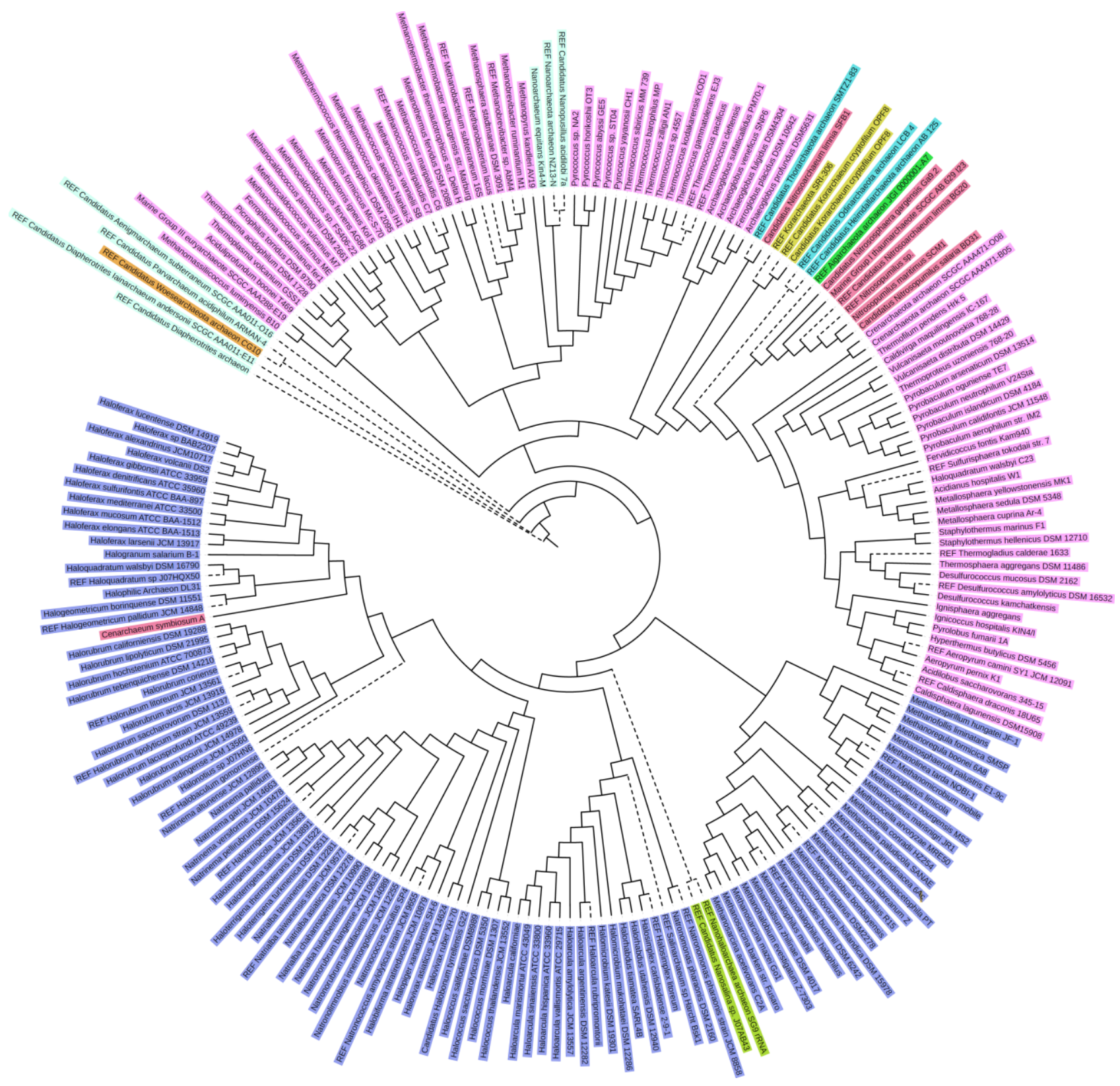

Euryarchaeota phylum

Crenarchaeota phylum

Thaumarchaeota phylum

Korarchaeota phylum

Aigarchaeota phylum

Woesearchaeota phylum
Superphylum ASGARD: Thorarchaeota, Odinarchaeota, Heimdallarchaeota, Lokiarchaeota (not shown)

Superphylum DPANN : Diepherotritse, Parvarchaeota, Aenigmarchaeota, Nanohaloarchaeota, Nanoarchaeota

Nanohaloarchaeaota phylum

16 s sequences from MetaPhIAn2 ID

- - - Reference $16 \mathrm{~s}$ sequences 
871 Figure 4. Phylogenetic tree of the Archaea domain species found in AD1, AD2, AD3, though

872 MetaPhlAn2 hit profile, based on nearly full-length 16S rRNA gene sequences, using maximum

873 likelihood method, constructed by K-2 + G evolutionary model with 1,000 bootstraps

874 replicates.

875

876

877

878

879

880

881

882

883

884 


\begin{tabular}{|c|c|c|c|c|c|c|c|c|c|}
\hline $\begin{array}{l}\text { Physicochemical } \\
\text { characteristics } \\
\text { of AD }\end{array}$ & IBV & Temp & SPC & Salinity & TDS & pH & LDO & $\mathrm{CH}_{4}$ & $\mathrm{CO}_{2}$ \\
\hline Water sample & 7.7 & 31.45 & 77.21 & 53.36 & 49.62 & 9.94 & 78.4 & 12.4 & $\begin{array}{c}\text { Not } \\
\text { detected }\end{array}$ \\
\hline Mat Sample & 8.0 & 34.35 & 77.31 & 52.55 & 48.76 & 9.75 & $\begin{array}{c}1: 165.3 \\
2: 7.3\end{array}$ & N/A & $\begin{array}{c}\text { Not } \\
\text { detected }\end{array}$ \\
\hline
\end{tabular}

\section{Supp. Table 1. Physicochemical parameters measured for Archaean Domes on April}

893 2016. IBV (volts); Temp: temperature ${ }^{\circ} \mathrm{C}$; SPC: specific conductance $(\mu \mathrm{S} / \mathrm{cm})$; Salinity (psu);

894 TDS: total dissolved solids (g/L); pH (0-14); LDO: dissolved oxygen (mg/L); CH4 ( $\mu \mathrm{g} / \mathrm{L})$

895

896

897

898

899

900

901

902 
bioRxiv preprint doi: https://doi.org/10.1101/766709; this version posted September 12,2019 . The copyright holder for this preprint (which was not certified by peer review) is the author/funder, who has granted bioRxiv a license to display the preprint in perpetuity. It is made available under aCC-BY-NC-ND 4.0 International license.

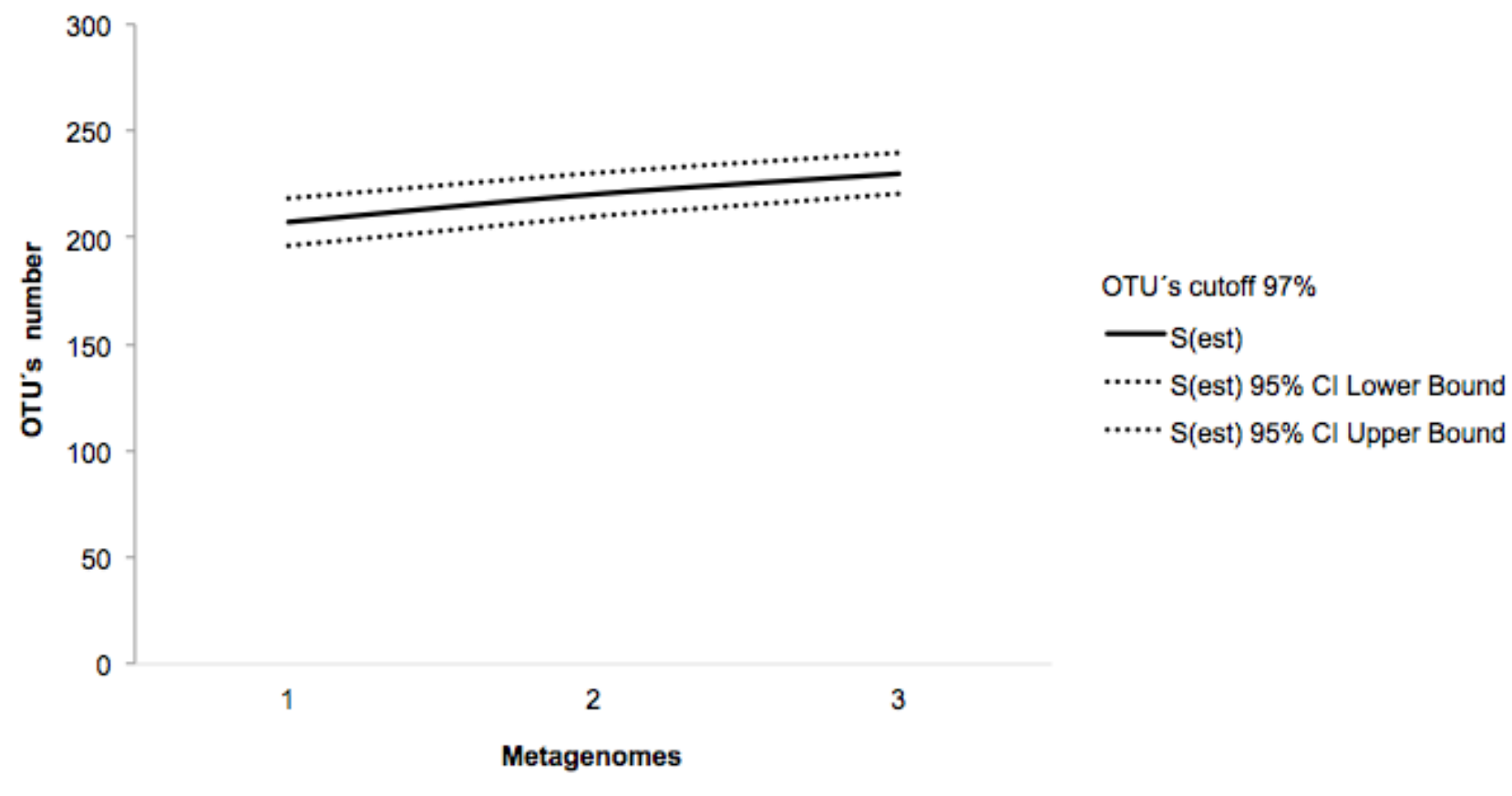

904 Supp. Fig. 1. Rarefaction curve to estimate the richness of Archean Domain in the different

905 season samples. 
bioRxiv preprint doi: https://doi org/10,1101/766709; this version posted September 12,2019 . The copyright holder for this preprint (which was not certified by peer review) is the author/funder, who has granted bioRxiv a license to display the preprint in perpetuity. It is made available under aCC-BY-NC-ND 4.0 International license.

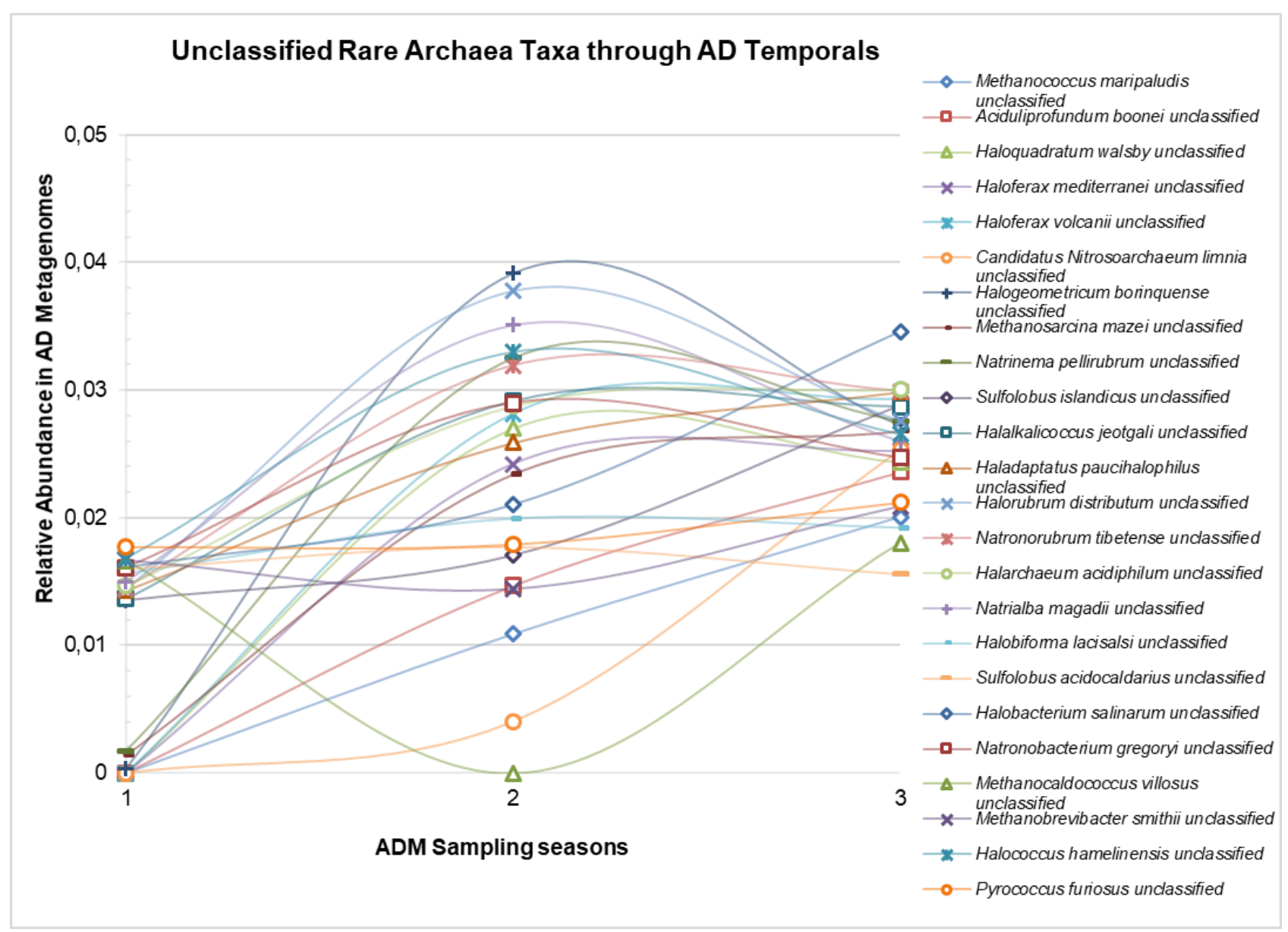

\section{Supp. Fig. 2. Unclassified Rare Archaea Taxa in the AD.}

909

910 